\title{
Structural Determinants of Poverty in the Savannah Region of Togo
}

\author{
Kpati Komlan Aguey \\ Master of Development Planning, University of Kara, Post code: 404, route no 1, Kara, TOGO \\ Corresponding author: Kpati Komlan Aguey
}

Received: January 01, 2020;

Accepted: January 15, 2020;

Published: 21January 2021

\begin{abstract}
The region of Savanes remains the poorest region of Togo, despite several years of colonial and post-colonial public interventions. The persistence of this multidimensional poverty has led to various questions about the real determinants that seem to limit the results of these various interventions. A review of the available literature and statistical datas, the interviewsl and focus group conducted in 2017 provided key information's that was triangulated. Subsequent analyzes and results obtained clearly showed that the question of poverty in this region is the result of two structural determinants.

The first determinant was the theoretical approach, the theory of growth poles, which has supported public interventions in this region. This approach has made the region of Savanes, a rural or peripheral region without large production processing unit and structurally dependent for its development of large urban centers. The second structural determinant is the mutation of local actors in a cycle of new dependencies on non-state actors for solving their domestic problems and development.
\end{abstract}

\section{Introduction}

The Savannah region of Togo has always been considered as the poorest region of the country. Kpetigo (1971) once mentioned that the Savannah region remains the least developed region of the country with a subsistence-based economic system despite the huge potential for farming. He specified that far-reaching actions for industrialization should be carried out to reduce regional inequalities and improve population living conditions. This was also the Togolese authorities' strategy, which, since the early fiveyear plans of the 1960s and 1970s, had invested several hundred million of francs CFA in order to invert the impoverishment trend. SORADs and then the decentralized Government services in charge of rural development, agriculture and others have, through several programs, supported the dynamics of development and regional inequality reduction in this region of Togo.

The most recent of the 2000s such as the PDRIS, the Millennium Communes Program, the PDC and PDC+ as well as the PUDC also aimed to reduce poverty through various measures. Those different programs have led to the strengthening of productive infrastructures and the improvement of regional organizational capacities. Today, there are several kilometers of roads, schools, clinics, small production units and commercial centers. Since 2015, the successive Governments have been keen to strengthen their social policy, which aims to improve the living conditions of people in rural and semi-urban areas as well as in disadvantaged areas. It was necessary to target a series of actions towards the poorest areas in order to ensure that Government actions could contribute to poverty reduction.

Despite these numerous interventions, the Savannah region remains the poorest region in Togo. Agbodji and all (2007) reported that the incidence of poverty at the household level was $69 \%$ in 1998 and $81.2 \%$ in 2006. By 2011, it was $87.3 \%$ and by 2017 it had risen to $65 \%$ (INSEED, 2018). Regardless of the time period and the various public measures taken in favor of this region, the issue of poverty remains important. There is a persistent trend of poor development over more than fifty years despite the results obtained from the various programs mentioned.

However, the Savannah region has the highest employment rate in Togo as well as the highest incidence of poverty. Does this paradox reveal that as more time is devoted to work, the more impoverished people become? This is the question at the core of this analysis. It consists in analyzing the socio-economic dynamics of the Savannah region in order to understand the structural determinants that have kept it in a situation of poverty for several decades.

This approach was based on an inductive approach, embedded in an explorative logic, which required a literature review, group interviews and individual interviews through representative samples of the region. The main results obtained are presented in the following paragraphs. They are preceded by an outline of the theoretical basis of the analysis and the methodology used to understand the structural determinants of the poverty phenomenon in the region.

\section{The theoretical foundations}

The question of analyzing the situation of poverty or wealth through the territorial prism requires an understanding of the sociohistorical dynamics of structuring and destructuring of this territory through regional policies. The analysis of the structural dynamics of the savannah region requires the understanding of the structural 
processes of construction of this territory. Côté (2018) specifies that all regional policy is traditionally the responsibility of the central Government. The objectives targeted by this type of policy in regional science, whether through spatial planning or economic development, are threefold. The first objective is the development of natural resources not yet exploited, the second aims to reduce regional inequalities, and the last relates to the support of developed communities in their process of continuous transformation. Each of these logics is supported by a theoretical approach that guides public intervention. It is these three logics, in the absence of previous work on these structural aspects of local authorities in Togo, that will serve as an analytical framework for understanding the situation in the Savannah region.

Therefore, the first logic of analysis is the one related to the issue of resource exploitation through a development process. This logic in regional science is close to the theory of the export base and maintains that Government sets up communication infrastructures that provide access to productive resources in the primary sector that are intended for export. The income from these exports should enable the acquisition of manufactured products and contribute to satisfy the domestic needs of the region exporting raw materials (North, 1955).

The second logic of Government intervention in regional science, as mentioned above, should enable the establishment of a certain number of infrastructures and facilitate the harmonized development of the territory through the reduction of regional inequalities. The most well-known theoretical approach that inspired the second logic is the growth poles approach. Developed by Perroux (1955), this approach stated that the Government should facilitate the establishment of industrializing infrastructures in a central zone of the territory and then develop interconnections between this central zone and peripheral zones. The production structures of the peripheral zones supply raw materials to those of the central zone, which process and sell them. The flows generated and the technological transfers allow, through exchanges, a smooth diffusion of development on the territory.

Finally, the last logic targeted by Government interventions, aims to allow the evolution of developed areas through an adjustment to new market standards or new technologies. Several post-Fordist theoretical approaches induced by this third logic can be listed. We can cite the models of industrial districts, clusters (Porter, 1990) and innovative environments (Aydalot, 1985). All these models are based on regional specification in relation to a given product with a control of the production chain of values. Investment in productive infrastructure tends to make the region as productive as possible and to cope with external competition.

These logics of Government intervention allows, in relation to the objectives, to shape the national space. Economic development at the regional level is always coupled with spatial planning processes. The measures taken enable the Government to make certain target areas viable and, unfortunately, to contribute to the devitalization of others. The effects on populations and the territory can be positive through the improvement of collective well-being or disastrous through the accentuation of poverty issues. For local authorities in sub-Saharan Africa, Aguey (2015) pointed out that the structural dynamics of the local or regional economy implies a diversification of economic activities often focused on the primary sector for real autonomy.

Once these Government intervention logics are understood, it is important to be able to identify the structural elements that have kept the Savannah region in a poverty cycle for more than fifty years.

\section{Methodology}

Understanding the structural determinants of poverty in Savannah regions required the use of specific scientific processes and tools. Through the inductive approach and a case study strategy (Hlady Rispal, 2003), this exploratory research was based on literature review and empirical data collection during the year 2017 and then, the year 2020. It consisted of a generation of explanatory causes of a phenomenon observed in this rural region of Togo. Gauthier (2006) specified that the case study allows "an exhaustive description of a situation, a problem, a geographical unit, etc.". "The important thing is to collect information on all aspects and to deal with them exhaustively. Yin (2003) mentions that the role of the case study is to bring accountability for complex interactions of a phenomenon in its time context. The question of identifying the structural determinants of poverty in Savannah regions, given its different manifestations, is a complex whole that deserves special attention for its analysis and understanding. This is what justified the preference for a single case study rather than a multi-case study. The analysis of each territorialized development process requires a singularized approach that could not be systematically generalized at the risk of neglecting several important explanatory factors. A good monographic and empirical knowledge of the issue of structural determinants of poverty in the Savannah region has generated very useful information for scientific community.

A first step consisted in the first quarter of 2017 in conducting a literature review. This review allowed the collection of monographic data and detailed statistics for the Savannah regions. It continued in the first quarter of 2019 , after the secondary data collection and analysis step.

The second step of data collection consisted in April 2017 of conducting 6 group meetings with about 50 representatives of youth, women, traditional and religious leaders, NGOs, Regional Development Committee and private sector. These regional meetings took place in Dapaong, the regional chief of the region.

A first group meeting made it possible to clarify the concept of poverty in its complexity and multiple dimensions. After this meeting, these actors were divided into 3 specific groups of 15 people to structure their remarks according to the perception of their stakeholder groups. The 3 discussion groups constituted were: public sector group, private sector group, civil society organizations group. The discussions in each group were summarized and trends by category of stakeholders were identified. These results were rediscussed in a plenary session and then approved by all the actors present.

In addition to these 5 group sessions, 63 individual interviews were conducted in each of the 7 prefectures of the region with a certain number of key informants identified beforehand through stratified sampling, respecting demographic data. All the results obtained were summarized and discussed one last time through a final focus group that mobilized about thirty members of the Regional Development Committee. It should be recalled that the visits to the various prefectures also allowed, through observation, to assess the quality of the basic social infrastructure.

In May 2020, additional data was collected in the 16 communes of the Savannah region, i.e. $100 \%$ of the sample, on the specified classical determinants of economic development. This survey allowed 169 questionnaires to be administered to regional planning departments, prefectures, local elected officials and senior managers of the communal public administration.

This method of collecting information enabled a better understanding of the causes of persistent poverty in the Savannah 
regions, the inadequacies of the various public and private interventions, and an analysis of the existing potential and opportunities for development. These results, when compared to the scientific literature available in regional sciences, led to the results presented below.

\section{Results}

\section{III-1- Regional Economy}

The economy of Savannah regions is essentially based on agropastoral production. The population is $72 \%$ agricultural. According to RNA data (2012), the main crops in the region are cereals for $99 \%$ of farming households, $93 \%$ for vegetables and
$69 \%$ for rainfed vegetables. $42 \%$ of farm households produce cotton, $54 \%$ grow fruit, specifically mangoes, and $24 \%$ of these households produce vegetables.

This crop production is also supported by cattle, goat and sheep breeding (Table 1) on one side and beekeeping on the other. The cattle herd is largely made up of transhumant animals from neighboring countries, specifically Burkina Faso and Niger. This breeding technique most often leads to access difficulties to pastures and water resources because breeders do not respect the official crossing corridors (Axis $\mathrm{N}^{\circ} 1$ : Cinkassé-Timbou-NanergouDapaong- Naki Est-Nagbéni Mango and Axis $\mathrm{N}^{\circ} 2$ : KoundjoaréBorgou-Naki Est-Nagbéni-Barkoissi-Mango).

Table 1: Share of Savannah Region Livestock in National Production

\begin{tabular}{|c|c|c|c|c|c|}
\hline Administrative level & Cattle & Sheep & Pigs & Goats & Poultry \\
\hline Savannah & 34962 & 33256 & 54668 & 49438 & 75481 \\
\hline National & 45802 & 118136 & 247135 & 119678 & 403372 \\
\hline$\%$ of Producer households in the Savannah compared to the national average & $76 \%$ & $28 \%$ & $22 \%$ & $41 \%$ & $19 \%$ \\
\hline
\end{tabular}

\section{Source: RNA Data, 2012}

Savannah regions remain Togo's leading beekeeping region with $43.3 \%$ of national beekeeping households. In terms of production techniques, only $3.7 \%$ of farming households have irrigated land in Savannah regions and the rest of producers practice rainfed agriculture.

The proportion of the productive labor force in relation to the rural population (Table 2) has been in constant decline for a

Table 2: Changes in the Agricultural Labour Force

\begin{tabular}{|l|l|l|l|}
\hline Year & 1981 & 1995 & 2012 \\
\hline Rural population & 299246,00 & 476135,00 & 746648,00 \\
\hline Agricultural labour force & 160913,00 & 197173,00 & 280259,00 \\
\hline Share of the agricultural labour force in the rural population & $54 \%$ & $41 \%$ & $38 \%$ \\
\hline
\end{tabular}

Source: RNA Data, 2012

Rural areas are also characterized by scattered housing in the form of small farms in which the space occupied by family concessions is reduced to the vital minimum in order to ensure optimal exploitation of the land assets located around the concessions. These fields are subject to a restrictive ownership of land. Only men, heads of families, have access to them through family succession and are responsible for their management and control. Production is essentially intended primarily to supply the family granary for self-consumption. This information confirms what Kpétigo (1971) described as a subsistence economy in 1971.

The second type of exploitation consists of large fields located outside the villages and reserved primarily for cotton cultivation. Under the supervision of the Nouvelle Société Cotonnière du Togo (NSCT), producers benefit through their organizational structures (cotton producer groups) from the supply of inputs (fertilizer, seeds, phytosanitary products). The areas of cotton plots generally vary from 1 to 5 hectares. Insufficient food crop production in the hut fields, due to poor soils and the absence of fallow land, leads farmers to practice an annual rotation between cotton plots and food crop plots. This production technique makes it possible to substantially improve their cereal production. Depending on the availability of land and/or the inadequacy of the family labor force, the vacant land in the family's land holdings is exploited indirectly.

The bankization rate remains one of the lowest in Togo with only $12.3 \%$ of the active agricultural population having a bank account according to the 2012 agricultural census data. number of years, reducing the region's productivity level without mechanization. This fall in the agricultural labor force is mainly attributed to the higher rate of school enrollment and the rural exodus of young people. The region's potential in the lowlands is still largely under-exploited due to the lack of hydro-agricultural facilities.
Commercial activities occupy second place with only $8 \%$ of local residents engaged in these activities (Figure 1). The region's largest commercial center is located in the border area of Cinkassé, in the northwestern part of the country. The main products distributed there are mostly manufactured goods from Asia destined for the Sahel countries. The prefectural and cantonal authorities have deplored the lack of commercial infrastructure to improve the contribution of local economic activities to national revenues. According to the Cinkassé Traders Association, the annual membership fees of their members exceed 50 million FCFA per year.

\section{III-2- The issue of poverty in Savannah regions}

Poverty is a complex phenomenon, which can only be understood in relation to several dimensions: material, social and cultural. Culture conditions the different perceptions that individuals may have of such a seemingly objective situation. The concept of poverty does exist in the cultures of the Savannah regions, which is reflected in local perceptions by the names: Yaari in Anoufo, Mitchetchekm in N'gam-gam, talarm in Ben/gourmantché and talmno in moré/yana.

At the level of macroeconomic aggregates, the incidence of poverty is reflected in low purchasing power, limited access to basic infrastructure (health, education) and a low standard of living. 


\section{Income poverty}

The Savannah region is the poorest in the country, with a particularly high incidence of poverty, around $73.18 \%$ according to the results of the 2015 QUIBB survey. This incidence, although down from previous years, remains the highest in Togo. According to the 2006 and 2011 QUIBB surveys, the Savannah region is one of the regions where poverty rates increased from $86.7 \%$ to $90.8 \%$.

At the national level, over the same period, poverty index rose from $61.7 \%$ to $58.7 \%$, falling to $55.1 \%$ in 2015 . In 2011 , among the 10 poorest prefectures in the country, the five in the Savannah region are: Kpendjal (96.2\%), Tandjoaré (94.5\%), Oti $(91.7 \%)$, Tône $(87.6 \%)$, and Cinkassé $(85.0 \%)$. The results of the 2011 QUIBB survey revealed that households in the Savannah regions $(58.5 \%)$ are in second place after those in the Maritime region $(63.4 \%)$ in terms of difficulties in meeting the food needs of their members.

\section{Low education and literacy levels}

In 2015, the net schooling rate in the Savannah region (90.3\%) is lower than in most other regions. This situation indicates the difficulty for parents to send their eligible children to school. Between 2010 and 2015, primary school completion rates in the Savannah region $(82.5 \%$ in 2015$)$ are lower than the national average ( $85.2 \%$ in 2015$)$. Similarly, the primary school completion rate for girls in the same region is lower than for Togo as a whole. The QUIBB survey (2011) shows that the region is home to some of the prefectures with the lowest net primary school enrollment rates in the country: $60.2 \%$ for Kpendjal, $63.3 \%$ for Oti and $74.2 \%$ for Cinkassé. In 2013, the Savannah region had the lowest literacy rate (24\% for women and $55 \%$ for men). Moreover, in terms of education, according to the QUIBB (2011) results, the adult literacy rate at the national level is $60.3 \%$ compared to $32.8 \%$ for the Savannah region (the lowest rate).

It is in the Savannah region that the highest percentage of people with no access to any media is recorded (70\% of women and $65 \%$ of men).

In terms of educational infrastructure, more than $40 \%$ of schools in the Savannah Region are Local Initiative Schools (EDIL) often run by low level teachers, which has a negative impact on the quality of education provided.

\section{Limited access to health care}

In terms of health, according to data from the 2015 statistical yearbook, the Savannah region, the poorest region in Togo, has only $18.94 \%$ of doctors. The number of inhabitants per health facility is 8389 for one doctor, higher than the national average of 5315. This reflects an unequal distribution of health facilities to the disadvantage of these regions. In the Savannah region the proportion of births attended by a trained provider is the lowest (36\%) in Togo. In the area of nutrition, in 2015, the Savannah region recorded a high rate of children receiving growth control and promotion services from health facilities. In fact, $45 \%$ of new cases in 2015 compared to $31.10 \%$ at the national level.

In fact, according to EDST III, $43 \%$ of children in the Savannah region suffer from malnutrition. Also, since underweight is strongly correlated with the level of household wealth, the high level of this indicator in the Savannah regions (23.5\%) and malnutrition is revealing the precarious situation in which these populations live. Indeed, in the richest quintile of the Togolese population, the underweight rate is three times lower (7.2\%).

An analysis by region reveals strong inequalities. The level of infant mortality varies from a minimum of $44 \%$ in the Maritime region to a maximum of $62 \%$ in the Kara region. The lowest child mortality quotient is recorded in the Lomé agglomeration (17\%) and the highest in the Kara region (72\%). In general, the lowest infant and child mortality rates are observed in the Lomé agglomeration (63\%) followed by the Maritime region (79\%). On the other hand, the highest infant and child mortality rates are recorded in the Kara region $(130 \%)$, followed by the Central region $(113 \%)$, the Savannah region $(107 \%)$, and finally the Plateaux $(96 \%)$.

While at the national level as a whole, child malnutrition leading to stunting is more pronounced in rural areas (28\%) than in urban centers (17\%), the Savannah region $(33 \%)$ is in second place after Kara (37\%).

Difficulties in access to healthcare are not the only reason for this and there are also regional inequalities. While at the national level, $66.1 \%$ of households feel that the health care needs by members of their household are not being met, the figure is $79.9 \%$ for the Savannah region and $69.5 \%$ for the Maritime region. The Kendjal prefecture is one of the ten prefectures in Togo with the lowest rate of access to health facilities (6.2\%). According to the Accelerated Growth and Employment Promotion Strategy (SCAPE) 2013 - 2017 document, 75\% of doctors are concentrated in the capital, compared to $7 \%$ in the Savannah region. The Savannah region has the highest rate of non-attendance of health services at $84 \%$.

\section{A Low standard of living}

Based on the results of the 2010 General Population and Housing Census and the QUIBB survey (2011), in terms of access to electricity, the coverage rate in the region is very low, with prefectures that are among those with less access to electricity. Among the ten prefectures with the lowest rate of access to electricity, those in the Savannah region are in the top two places: Kpendjal (1.1\%), Tandjoare (1.3\%). According to data from the Household Survey on Energy Consumption in Rural Areas in Togo, only $1.5 \%$ of households in the Savannah region use electricity from the electricity company as a source of lighting.

In the Savannah region, only about 1 in 2 people have access to a drinking water point.

In this region, the population lives on the main sources of income : the sale of agricultural products, livestock products, trade in processed products (shea, nere, groundnut, beans, sorghum). These very low incomes do not allow them to meet their needs for food, health, housing, clothing, education, funeral ceremonies, weddings, preparation of the fields for the new season, leisure activities, and to acquire goods and equipment. Among the acquired goods and equipment, the woman uses only those that serve her in her domestic work. The rest of the resources are used by the heads of households.

The region's social infrastructure (economic, educational, water and sanitation infrastructure) is fairly poor. Entire localities lack infrastructure. The rare existing infrastructures are damaged and cannot meet the needs of the existing communities. Economic and human constraints such as : (i) the low level of education of the population, (ii) the lack of electric power for the development of small-scale industry, (iii) inadequate health coverage, (iv) the poor organizational capacity of farmers and herders, and (v) the poor state or non-existence of communication channels justify this precarious situation in terms of household living conditions.

Moreover, with a population growth rate of $3.18 \%$ (the highest rate among Togo's five economic regions (Accelerated Growth and Employment Promotion Strategy Paper 2013), some parts of the region are already suffering from strong demographic pressure. 
All the consultations conducted with community representatives (women, youth, traditional chiefs, heads of Development Committees and the private sector) and local stakeholders (NGOs, Regional Committee for Development and Land Management) as well as resource persons chosen from the 5 prefectures of the region are all agreed that the Savannah region is a region with an agricultural vocation and remarkable potential. For this reason, the lack of development of the agro-pastoral potential of the region is the main cause of persistent poverty, which is due to the lack of water control and soil impoverishment. This observation is also confirmed in most of the analyses carried out in the region.

\section{Discussions: Structural Determinants of Poverty}

The analysis of the various information gathered has clearly shown that the manifestations of poverty are reflected in a number of socio-economic facts that lead to two essential consequences. The first consequence, which is youth unemployment, would be the basis of:

An important exodus of the population to other regions or countries;

The prostitution of young girls;

The incivility and recurrent violence;

Alcoholism among young people;

Lack of sales of agricultural products;

Resignation and lack of entrepreneurial initiatives.

The second consequence is poor access to basic social services despite numerous public programs that have been developed since at least 1966. This would be the result:

The low level of education;

Illiteracy;

A high percentage of deaths due to lack of adequate care.

These two elements constitute the main consequences of the persistence of poverty in the Savannah region.

Other causes of poverty, mainly related to the difficulty of selling products and the lack of adequate means of storage and conservation, cause farmers to sell their products and a few months later find themselves on the same market buying them at two or three times the price.

Funeral arrangements were also mentioned as a social practice that consumes a large part of household income and in most cases can even plunge families into debt.

Inefficiency in the implementation of programs was strongly emphasized by community representatives as one of the main causes of poverty because it does not allow people to derive maximum benefit from the various initiatives. In this regard, they mainly cited: the failure of technical studies for the development of lowlands and the construction of water reserves; the noninvolvement of communities in the execution of programs, poor financial management, the lack of synergies between stakeholders, complacency in monitoring and the absence of an effective sustainability strategy.

\section{IV-1- The theoretical basis for public intervention}

The incidence of poverty increases as you get further away from the city of Lomé. The regional incidence of poverty recorded is significantly higher than in Lomé. The 2011 QUIBB surveys clearly showed the persistence of poverty, especially in rural areas.
The northern regions are the most affected by this incidence of poverty. In the Savannah region, it is $87.3 \%$ against $45.3 \%$ for the Maritime region. In contrast to this trend, data from the 2011 QUIBB surveys also reveal that the employment rate is highest in the Savannah region, where it is $74.3 \%$. A complementary observation reveals that the three southern regions of the country have an employment rate higher than the incidence of poverty, while in the three northern regions, the incidence of poverty is higher than the employment rate. This raises questions about the nature of this correlation.

Why do jobs in the Savannah region fail to reduce poverty? What are the determinants of this reverse progression?

The answers to these questions are above all structural. An analysis of the Togolese economic structure shows that the production structure in the Savannah region is essentially based on the primary sector, specifically agriculture and artisanal mineral extraction.

At agricultural level, production techniques are essentially oriented towards subsistence agriculture. The modern private sector is not very dynamic and therefore not very productive in terms of creating decent jobs. Most of the activities are informal and are therefore not accounted for in national income. The incidence of poverty among self-employed agricultural workers, although declining, remains the highest compared to other socioeconomic categories. Unemployed people have better living conditions than these self-employed producers. This incidence of poverty among agricultural workers can be explained by two key factors:

- the weakness of the mechanisms of processing and conservation of agricultural products that do not allow producers to make the maximum profit from them ;

- The limited structuring of agricultural jobs that are poorly integrated into the formal national system and do not allow these assets to benefit from social protection measures.

Apart from the agricultural sector, it should be noted that extractive companies are capital-intensive enterprises that absorb little local labor. The incidence of poverty among private sector employees is on the rise, unlike all other socio-economic categories. This raises questions about the quality of jobs in the private sector. The information collected on the evolution of poverty clearly shows that these jobs do not provide a decent standard of living.

As a result, employment rates are high in the northern regions, but they are essentially low-productive jobs that do not allow these actors to escape poverty.

The regional economy in the Savannah zone is therefore oriented in relation to the growth pole model (Perroux, 1955). De Han (1993), through a historical analysis of the structuring of the Savannah region, has shown that since the 15th century, this region has served as a transit area for trade negotiations and as grazing areas for cattle breeders. The French colonizer introduced the cultivation of groundnuts and then cotton, crops intended for export. This trend was maintained in the post-colonial state with different techniques and forms of production.

In the structuring of the national or regional economy of West Africa, the Savannah region has always been considered as a peripheral region that should serve as a supply area for the major urban centers or poles. Through trade, it should develop but the theory does not specify the temporal dimension that should drive 
this development. The historical reading of de Han (1993) has clearly shown that at least from 1884 to the present day, the economic vocation granted by the public authorities to the Savannah region has been that of peripheral regions with a rural vocation. The limitations of this Keynesian-inspired model relate to the non-integration of the spatial and temporal dimensions of development issues (Polèse and Shearmur, 2003). It is this model that continues to inspire most public interventions in the Savannah region.

The first structural determinant of poverty in the Savannah region is thus linked to the nature of the theoretical model that guides regional interventions in Togo. In the practice of this theory, the Savannah region, being considered as a peripheral or rural region according to the terminology adopted, its development cannot quietly be envisioned. The various spaces throughout the world, whether in the West or elsewhere, have clearly shown that the paradigm has always been unfavourable to peripheral regions (Jean, 2018).

\section{IV-2- The new dependencies of local development}

Moreover, during consultations with the different categories of stakeholders, the following reasons were cited as the causes of the mixed results of the development programs implemented in the Savannah region and the persistence of poverty :

- Projects are designed around new and exogenous concepts that are often not consistent with the realities of the beneficiaries;

- Local actors are not involved in the monitoring or financial management of the programs. On the technical level: The failure of technical studies for the development of lowlands and the construction of water reservoirs, which was the basis of unfinished or poorly executed work, has led to wasted resources and strong frustration among the population.

It should also be noted that the various actors involved in the implementation of the various development programs and projects work in isolation without any co-operation, sometimes even in a competitive manner. This tendency leads to duplication and waste of resources and thus to a drastic reduction in the expected impact.

The sustainability strategy, which consists of putting local actors at the center of the action, transferring skills and means to them and having a system of control and appreciation exercised by the communities with complete freedom, does not exist in most programs. As a result, the projects end when the external funding ends and the populations find themselves at the same level, if not worse than before, with the appearance of new kinds of frustrations.

In addition, it emerged from the focus groups and interviews that collaboration between program managers and state technical services is not always obvious, and the latter are not always aware of the initiatives carried out by the central administrative level.

These elements of assessment of the poverty situation noted by local actors clearly showed that the latter are still waiting for exogenous programs and projects. They hope that the solution will come from the Government, NGOs or their diaspora. They have signed up. In the course of the evolution of public interventions, in a cycle of dependence on institutional actors (Aguey, 2015). This wait-and-see attitude continues through a certain permanence that can be perceived in the speeches of local actors. Expectations are no longer necessarily oriented towards the central state, but rather towards development organizations and the local diaspora. These are the new forms of dependency linked to local economic development (Aguey, 2015). The second structural determinant of poverty in the Savannah region is therefore linked to the new forms of dependency induced by local actors and which suppresses any initiative that could allow a reversal of the poverty cycle.

\section{Conclusion}

The Savannah region, located in the north of Togo, has always been considered as the poorest region of the country. Many measures taken by the state and numerous interventions by nongovernmental actors have never made it possible to reverse this trend. A historical review of the territorial dynamics of this region has shown that the economy has always been oriented towards the exploitation of raw materials. Initially a transit zone for caravanners before the 19th century, it then became a raw material supply area under the German presence. While diversifying the local rain fed crops, the colonial and post-colonial administrations did not change the economic structure there. Poverty therefore remained constant. More than monetary poverty, this poverty is also relative to the accessibility to basic social services, quality of life and socio-cultural prisms.

With independence, the structural model promoted for territorial management in Togo and maintained at the level of the regional economy was the growth poles model developed by Perroux (1955). In practice, this model was more or less beneficial for urban areas and rather unfavourable to rural areas known as peripheral regions. The model, inspired by Keynesian thought, as conceived by Perroux did not take into account the temporal dimension of any development process. Applied through various public measures and programs to the Savannah region, it constituted the first structural determinant for maintaining the region in poverty.

The second structural determinant limiting the development of the Savannah region is the mutation of exchange dynamics towards new dependencies. These structural dependencies of local authorities lead them to a certain wait-and-see attitude towards non-governmental organizations, their diaspora and technical and financial partners. Regional actors, instead of working to boost their economy and create wealth, prefer to solicit the support of these different actors, keeping them in the infernal cycle of poverty through this structural dependence.

The Savannah region is thus kept in poverty through two structural determinants: the theoretical basis of public intervention and the insertion of local actors in the dynamics of new dependencies.

\section{Conflicts of Interest}

I, Kpati Komlan Aguey, declare that there is no conflict of interest regarding of this paper.

\section{Bibliography}

[1] Agbodji A., Yovo K., Abalo K., Agbodji K., Johnson A., 2007, 'Stratégie sectorielle, Pauvreté et Vulnérabilité : cas du Togo", Rapport 6th Pep Research Network General Meeting.

[2] Aguey K, 2015, Le développement économique local dans les collectivités rurales en restructuration de 
l'Afrique subsaharienne : cas de la commune de GrandPopo (République du Bénin). Thèse, Rimouski, Canada.

[3] Amin S,1988, L'échange inégal et la loi de la valeur, Éditions Anthropos, Paris, France.

[4] Aydalot P., 1985, Économie régionale et urbaine, Économica, Paris, France.

[5] Côté S., 2018, "À l'heure de la mondialisation, les politiques régionales de l'État Central sont-elles devenues caduques?", in la Voie du Grideq : du développement régional au développement territorial, Cahiers du Grideq, Rimouski, Canada.

[6] De Haan L., 1993, La Région des Savanes au Togo : l'État, les paysans et l'intégration régionale (1885-1985), Éditions Karthala, Paris, France.

[7] Gauthier B., 2006, Recherche sociale : de la problématique à la collecte des données, Éditions Presses de l'Université du Québec, Québec, Canada.

[8] Hlady-Rispal M.,2003, Les Études de cas : Application à la recherche en gestion, Éditions de Boeck Paris, France.

[9] Jean B., 2018, 'Le développement régional à l'heure du développement local :'’le temps des incertitudes',

[10] in la Voie du Grideq : du développement régional au développement territorial, Cahiers du Grideq, Rimouski, Canada.

[11] Kpétigo E.,1971, Le calcul économique appliqué à la planification en Afrique noire. Un exemple : le Togo.
Thèse, Université Paris 1/Panthéon-Sorbonne, Paris, France.

[12] Ministère de l'Agriculture, de l'Élevage et de la Pêche, 2013, 4ème recensement national de l'Agriculture 2011 2014.Profil de l'Agriculture Togolaise. Lomé, Togo.

[13] Ministère de l'Agriculture, de l'Élevage et de la Pêche.2014. 4ème recensement national de l'Agriculture 2011-2014. Volume VI : Module Complémentaire. Principales Caractéristiques de l'Agriculture Togolaise. Lomé, Togo.

[14] North D., 1955, "'Location Theory and Regional Economic Growth", in Journal of Political Economy, vol. 63,243

[15] Perroux F., 1955, Note sur la notion de pôle de croissance ? In: McKee, D., Dean, R. and Leahy, W., Eds., Regional Economics: Theory and Practice, The Free Press, New York, 93-104.

[16] Polèse M., Shearmur R., 2009. Économie urbaine et régionale. Introduction à la géographie économique, Économica, Paris, France.

[17] Porter M.,1990, L'avantage concurrentiel des nations, InterEditions, Paris, France.

[18] Yin R., 2003, Case Study Research : Design and Methods, Sage, California, USA. 